Int. J. Electrochem. Sci., 15 (2020) 3681 - 3693

\title{
Preparation of Eosin Y/Graphene Oxide Modified Glassy Carbon Electrode as a Sensing Platform for Dopamine and Epinephrine Detection
}

\author{
Shengbiao Zheng, Yu Liu, Jing Liu, Jing Tang* \\ College of Chemistry and Material Engineering, Anhui Science and Technology University, 233000, \\ Bengbu, Anhui Province, China \\ *E-mail: zhengtang102@163.com (Tang Jing)
}

doi: $10.20964 / 2020.05 .27$

Received: 5 January 2020 / Accepted: 2 March 2020 / Published: 10 April 2020

The electrodeposition of eosin Y (EY) on graphene oxide (GO) modified glassy carbon electrode (GCE) was performed and the modified platform applied for the simultaneous determination of dopamine (DA) and epinephrine (EP). The EY/GO modified GCE was characterized using electrochemical impedance spectra. The modified electrode exhibited excellent electroanalytical performance for DA and EP by cyclic voltammetry due to the synergistic effect of the good electrical conductivity of GO and electrochemical activity of EY. The linear responses were found by differential pulse voltammetry (DPV) between 0.2 and $100 \mu \mathrm{M}$ concentration range for DA and EP, with detection limits of $50 \mathrm{nM}$ for DA and $30 \mathrm{nM}$ for EP (S/N = 3), respectively. Further experiments were investigated for electrode selectivity, stability and reproducibility. In addition, in order to evaluate electrochemical activities for this proposed electrode, the simultaneous determination of DA and EP at EY/GO/GCE was explored in diluted human urine samples.

Keywords: eosin Y; graphene oxide; dopamine; epinephrine; modified electrode

\section{$\underline{\text { FULL TEXT }}$}

(C) 2020 The Authors. Published by ESG (www.electrochemsci.org). This article is an open access article distributed under the terms and conditions of the Creative Commons Attribution license (http://creativecommons.org/licenses/by/4.0/). 